\title{
Psychological Capital and Entrepreneurial Success: a Multiple-Mediated Relationship
}

\author{
Hasni N. Juhdi and Roshayati Abdul Hamid \\ Faculty of Economics and Management, Universiti Kebangsaan Malaysia
}

Adriana Mohd Rizal

International Business School, Universiti Teknologi Malaysia

Nurita Juhdi

Kulliyyah of Economics and Management Science, Islamic International University Malaysia

\begin{abstract}
This study examined the relationship between psychological capital and entrepreneurial success and the roles of entrepreneurial work engagement and entrepreneurial learning intensity as multiple-mediators in influencing the relationship. In addition, the effects of service orientation and market orientation on entrepreneurial factors were also tested. Respondents were the owner-managers of small and medium service enterprises (service SMEs) in Malaysia. Simple random sampling was used, given a sampling frame which contained 502 service SMEs. A questionnaire survey involving 125 entrepreneurs with more than five years of entrepreneurial experience in service businesses provided useful data. The data were analyzed using SPSS and SPSS Macro. The results showed that psychological capital had a positive relationship with entrepreneurial success. In fact, through entrepreneurial work engagement and entrepreneurial learning intensity, the multiple-mediators, the relationship was found to be more comprehensive. Application of bootstrapping procedure in SPSS Macro had found that entrepreneurial work engagement and entrepreneurial learning intensity were simultaneously significant multiple-mediators but entrepreneurial work engagement had higher impact than entrepreneurial learning intensity on the relationship between psychological capital and entrepreneurial success. In conclusion, this study supported the theoretical arguments that entrepreneurial success are strongly associated with internal power and strengths, which this study believed as psychological state resources. However, the relationships between firm orientations such as service and market orientations and entrepreneurial factors require further investigation in future studies.
\end{abstract}

Keywords: psychological capital, entrepreneurial success, multiple-mediators, entrepreneurial work engagement, learning intensity, service orientation, market orientation

\section{Introduction}

Entrepreneurial success of small and medium-sized enterprises (SMEs) sounds exciting to research because the concept is complex. At individual level, many entrepreneurs voluntarily keep faith in their ventures hoping for success, despite the facts that they themselves know, few would get through while the majority march into the death-valley as observed by Lerner (2009). At organizational level, entrepreneurial success is a myth due to conflicting interests between the ownermanagers and strategic decision makers regarding problem/opportunity-solution/exploitation nexus (Shane, 2003). Occasionally, there are success stories and they are documented exclusively in books and films but not much examined theoretically as yet. Thus, until now little is understood about the complexity of entrepreneurial success as well as its fundamentals, which involve several different knowledge spectrum (Fisher, Maritz, \& Lobo, 2013; Frese \& Gielnik, 2014; Sok, O'Cass \& Sok, 2013).

Many people are interested in entrepreneurship, awaiting for constructive explanations to these questions: What does entrepreneurial success actually mean, if money is not the issue? What do successful entrepreneurs have so much in common that others do not? How do they do things with limited resources and capability? Previous research define entrepreneurial success from strategic performance perspective and they conclude that personal traits determine the level of business performance (Idar \& Mahmood, 2011; Zheng \& Yin, 2010). However, from the individual entrepreneurs' 
perspectives, their concerns nowadays are much more about the meaningfulness of life rather than growth, financial performance, and wealth creation alone, and this in turn, calls for changes in understanding entrepreneurial success as a concept (Haber \& Reichell, 2005; Fisher, Maritz, \& Lobo, 2013). Thus, recent research highlight that entrepreneurial success should be given new definitions, and therefore, more comprehensive explanations. From the lens of psychology, a lot more could be understood about entrepreneurial success and the fundamentals of entrepreneurial success (Frese \& Gielnik, 2014), while attaching meaningfulness of life in discussing it. Generally, it is acknowledged that SMEs lack of resources and capability to innovate and succeed in their entrepreneurial ventures (Sok, O'Cass \& Sok, 2013) but the success stories of the few cannot simply be overlooked and they call for further research especially within the framework of psychology. Therefore, this study aimed to address those questions by examining the degree of multi-relationships between psychological state factors, firm orientations, and entrepreneurial success in order to broaden entrepreneurship theory.

Taken into consideration in this study were complexity of entrepreneurial success and limitations of cross-sectional study approach. Thus, multiple-mediation hypothesis testing model was used to do the data analysis which was available at SPSS Macro. Methodologically, SPSS Macro has the ability to examine multiple-mediation effects of more than one mediators simultaneously (Preacher \& Hayes, 2008). Overall, this study integrated entrepreneurship with the other fields of studies such as psychology, behavioral management, learning, and marketing to understand entrepreneurial success. Specifically, this study examined entrepreneurial success as the theoretical outcome of psychological capital and entrepreneurial work engagement together with entrepreneurial learning intensity as mediators in strengthening the psychological capital - entrepreneurial success relationship. Since explanations of entrepreneurial success is always in conjunction with strategic marketing activities, this study included market orientation and service orientation to verify the descriptions of each mediator in relation to entrepreneurial success accordingly.

\section{Entrepreneurial success}

What does entrepreneurial success mean, if money is not the issue? This study agreed with a view which says that entrepreneurial success is a set of positive outcomes from the utilization of internal human strengths guided by virtue (Seligman \& Csikszentmihalyi, 2000). The power and strengths are embedded deep within the psychology of individual entrepreneurs (Hmieleski \& Carr, 2007). Entrepreneurs perceive success not only financially but also psychologically (Gorgievski et al., 2011). For entrepreneurs, non-monetary incentive is more fulfilling, while monetary gains do not always bring the greatest satisfaction (Alstete, 2008; Csikszentmihalyi, 2003). Meanwhile, career success literature highlights that people appreciate more subjective success than objective measures of performance, given their full commitment to their work (Poon, 2005). In other words, successful entrepreneurs often feel more satisfied after all hardship and much more satisfied after sharing the abundance of money or wealth with the society in the forms of charity, donations, sponsorship etc. and at the same time, transmitting the feeling of gratitude to the society for being successful (Csikzentmihalyi, 2000). Thus, entrepreneurial success is highlighted to comprise not only financial gains but also psychological measures of success, such as satisfaction, feeling of gratitude, and preparedness (Sisodia et al., 2007; Tang et al., 2010). In regards, reliability of entrepreneurial success with the inclusiveness of psychological measures of success is still under researched.

Entrepreneurial success is dynamic because it depends on the fluctuation of psychological states, which determine behaviors amidst uncertainties, difficulties, changes, and challenges in the environments. In positive psychology theory, satisfaction is a higher level state of being successful relative to what the entrepreneurs have tried to achieve (Cooper \& Artz, 1995; Davidsson, 2005). Although satisfaction is relevant, it per se provides an incomplete description of entrepreneurial success (Gorgievski et al., 2011; Judge et al., 2001). Therefore, this study proposed a couple of other psychological aspects such as feeling of gratitude and entrepreneurial preparedness. Feeling of gratitude is a positive emotion as a result of the belief in achievement after hard work (Weiner, 1985). As a mental state, feeling of gratitude is a high level of personal ability which means a very meaningful achievement (Anderson et al., 2007; McCullough et al., 2002; Sisodia et al., 2007). Lastly, entrepreneurial preparedness is an entrepreneurial standard quality in making evaluation and judgment whether to exploit on opportunities based on available information (Judge et al., 2001; Tang et al., 2010). Thus, financial performance, satisfaction, feeling of gratitude, and preparedness together are deemed relevant as four criteria of entrepreneurial success in this study. 


\section{Psychological capital and entrepreneurial success}

What do successful entrepreneurs have in common? Psychological states are valuable personal resources critical to small firm success (Runyan, Huddleston \& Swinney 2007) and psychological capital is an established state construct (Carr 2011; Luthans, Luthans \& Luthans 2004) that is most fundamental at personal level from the perspective of resource-based view. Psychological capital in a way is an expansion of the concept of "economic capital", but it differs from human capital or social capital (Luthans et al. 2004). In other words, psychological capital is the belief that one has all the mental strengths, the capacity, and the capability to do something for the betterment of oneself and others. According to Luthans et al. (2004), economic capital refers to "what people have", human capital refers to "what people know" and social capital refers to "who people know". Psychological capital is concerned with people knowing "who they are". Psychological capital has four dimensions: self-efficacy, optimism, resilience, and hope (Luthans et al. 2004; Luthans, Avolio, Avey \& Norman 2007). In extant literature, psychological capital is the key determinant of entrepreneurial success of small and medium businesses (Hall \& Chandler 2005; Hmieleski \& Carr 2007; Peterson, Luthans, Avolio, Walumbwa \& Zhang 2011). Psychological capital drives people to succeed in the pursuance of meaningful life (Seligman \& Csikzentmihalyi, 2000). In entrepreneurship literature however, more empirical evidence is required to prove the significance of positive relationship between psychological capital and entrepreneurial success (Hmieleski \& Corbett 2008; Newman, Schwarz \& Borgia, 2014).

Thus, literature strongly suggest that psychological capital has a direct positive relationship with entrepreneurial success. Other than that, psychological capital relates positively to work performance (Luthans et al. 2004; Peterson et al. 2011; Sweetman et al. 2011); desired psychological outcomes (Avey et al. 2010); and the general well-being of human (Culbertson et al. 2010). The most recent empirical evidence in entrepreneurship study shows a positive relationship specifically between psychological capital and satisfaction among entrepreneurs (Hmieleski \& Carr 2007). Based on the above evidences, it is appropriate to posit that there is a significant direct relationship between psychological capital and entrepreneurial success. The following hypothesis was then deduced.

Hypothesis 1: Psychological capital is positively related to entrepreneurial success.

\section{Psychological Capital and Mediators:}

\section{Entrepreneurial Work engagement and Entrepreneurial Learning Intensity)}

How successful entrepreneurs work with limited resources and capability? In some extent, it is concluded that entrepreneurs are just being overconfident (Artiger \& Powell, 2015). Indeed psychological capital becomes the only critical resource left for the entrepreneurs in deciding whether to face the uncertain, risky, unstable environments locally and globally nowadays. However, those who lack of psychological capital would not dare to exploit opportunities (Newman, Schawrz \& Borgia, 2014), cannot endure the challenges of being entrepreneurs (Lerner 2009), and cannot do things greater than ordinary in life (Culbertson et al. 2010). Having high psychological capital means having all four elements of it namely self-efficacy, optimism, resilience, and hope.

In specific, high self-efficacy can affect motivation in completing difficult tasks, the stronger self-efficacy the more likely a person to make extra effort (Lope Pihie \& Bagheri 2012). Similarly in the context of entrepreneurship, because conviction to act is highest when entrepreneurs believe that their actions (e.g., exploiting a new opportunity) lead to attainable outcomes, high self-efficacy is an important determinant of required entrepreneurial behaviors. Since self-efficacy positively affects diverse behavioral functions, this study suggests the other elements of psychological capital which also have the same direction on entrepreneurial behaviors. Optimism, for instance, relates to ability to delay gratification and to forgo short-term gains in order to achieve long-term goals (Carr 2011; Peterson et al., 2011). Resilience helps entrepreneurs emerge into positive and progressive transformation despite being exposed to risks, adversity and uncertainty during entrepreneurial venturing (Peterson et al., 2011). Hope on its own is a construct closely related to optimism which acts as therapy to help entrepreneurs formulate clear goals, produce pathways toward the set goals, motivate them to pursue their goals, and reframe adversity and problems as positive challenges to be overcome (Peterson et al., 2011). Therefore, selfefficacy, optimism, resilience, and hope are combined together as psychological capital which was posited to relate positively with entrepreneurial work engagement.

Hypothesis 2a: Psychological capital is positively related to entrepreneurial work engagement. 
The entrepreneurial journey is full of adversity and critical events which put great challenge to the morale of entrepreneurs (Holcomb et al. 2009) but there is where the good sources of effective learning are situated (Sarasvathy, 2004; Stokes \& Blackburn 2002). Most successful entrepreneurs spin out their innovations risking their investments just for good entrepreneurship lessons not found in books (Sarasvathy, 2004; Stokes \& Blackburn 2002). Embracing that nature in entrepreneurial venturing, entrepreneurs find it necessary to have high level of self-efficacy, optimism, resilience, and hope (elements of psychological capital) along the way. For the purpose of learning-by-doing, entrepreneurs exploit opportunities based on heuristics, empowered especially by the elements of hope and optimism within psychological capital concept. In other words, entrepreneurs with strong psychological capital have strong drive to learn by doing and to learn from failures regardless the costs (Carr 2011; Politis 2005; Stokes \& Blackburn 2002). Thus entrepreneurial learning intensity necessitates entrepreneurs to have strong psychological capital to be capable in allocating, channeling, and combining scarce resources at personal level towards further exploitation and exploration of business opportunities at organizational level.

Hypothesis 2b: Psychological capital is positively related to entrepreneurial learning intensity.

\section{Entrepreneurial Work Engagement and Entrepreneurial Success}

A successful entrepreneur has the inner strengths developed to allow him/her to devote energy, effort and focus on something benevolent he/she has been aiming for and to lead strategic actions in attaining positive outcomes or success (Seligman \& Csikszentmihalyi 2000). By the way, no success is without hard work (Liechti, Loderer \& Peyer 2011). Hard work is an abstract concept but according to Cavana et al. (2001), such an abstract behavioral concept can be reduced to measurable ones given the appropriate theoretical justifications. For the purpose of this study, hard work was partly represented by entrepreneurial work engagement. Entrepreneurial work engagement is demonstrated when an entrepreneur performs work activities voluntarily with passion, attentiveness, and absorption. The importance of entrepreneurial work engagement in explaining entrepreneurial success is empirically supported. Breugst et al. (2011) explain that when an entrepreneur shows his passion and hardship for the business development, he actually has influenced the work teams to be more committed to achieve goals and targets, by which eventually resulting in the next entrepreneurial glory.

Similarly, each entrepreneur ought to view his/her ventures as very meaningful in his life and the life of others (family, workers, and customers). In general, people who venture into business and eventually become successful entrepreneurs are pulled by opportunities and desire to have good life and not necessarily pushed by unemployment or life-style requirements (Gorgievski et al. 2011). It is compelling therefore for entrepreneurs to invest all types of resources available and labor all their strengths, dedication, and absorption to accomplish their business goals. Thus, the following hypothesis was sought to examine the relationship between entrepreneurial work and engagement entrepreneurial success.

\section{Hypothesis 3: Entrepreneurial work engagement is positively related to entrepreneurial success.}

\section{Entrepreneurial Learning Intensity and Entrepreneurial Success}

The issue of learning has been discussed by Levitt and March (1988), who emphasize that organizational learning is the underlying process which explains firm success. At the individual level, learning determines the next level of entrepreneurial success (Sarasvathy 2004; Stokes \& Blackburn 2002), which can only be achieved through high-level of entrepreneurial learning (Cope 2003). Past researchers describe that entrepreneurs learn from direct experiences and experiences of others and enforce the new knowledge into actions, i.e. learing-by-doing. As an effect, it is found that a high-level entrepreneurial learning can improve business outcome (Cope 2003; Wang 2008). How rough is the entrepreneurial journey and how intense is the learning process, entrepreneurs rely only on limited knowledge and make decisions quickly without doing exhaustive analysis (Cope 2003; Holcomb et al. 2009; Stokes \& Blackburn 2002), especially within the context of service SMEs where enter - compete - exit is the dynamic nature. That being said, entrepreneurial success is the outcomes of high intensity of learning, as implied in Frese's concept of entrepreneur-in-action (2009) and by Cope's (2003) concept of high-level learning. Empirical evidence shows a positive link between learning-by-doing and performance (Dutton, Thomas \& Butler 1984) as well as between experiential learning and non-financial performance (Spicer \& Sadler-Smith 
2006). Therefore, it is appropriate to posit in this study that entrepreneurial learning intensity is positively related to entrepreneurial success.

Hypothesis 4: Entrepreneurial learning intensity is positively related to entrepreneurial success.

\section{Indirect Effects of Psychological Capital on Entrepreneurial Success through Entrepreneurial Work Engagement and Entrepreneurial Learning Intensity}

The study was driven to examine the possibility that the relationship between psychological capital and entrepreneurial success is mediated by two mediators: entrepreneurial work engagement and entrepreneurial learning intensity. Previous research in behavioral literature show that work engagement mediates the relationship between individual resources and desired behavioral outcomes (Salanova, Agut \& Peiro 2005). In addition, following the theoretical assumption and testing procedures for multi-mediation mechanisms by Preacher and Hayes (2008), this study had to examine whether the mediators were positively correlated. Entrepreneurial learning intensity and entrepreneurial work engagement need to be correlated because they ought to explain entrepreneurial success mutually and simultaneously (Preacher \& Hayes, 2008). To match such theoretical proposition which requires that the multiple mediators to be correlated, the following hypothesis was tested.

\section{Hypothesis 5a: Entrepreneurial work engagement and entrepreneurial learning intensity are correlated.}

Given both mediators are positively correlated, entrepreneurial learning intensity can now be posited to influence entrepreneurial success because empirically entrepreneurial work engagement (complementing mediator) has been reported to relate to performance positively as well. Based on the explanations and descriptions of Hypothesis 5a above about the roles and relationship of entrepreneurial work engagement and entrepreneurial learning intensity as correlated multiple-mediators, the following multiple-mediation hypothesis was finally derived:

Hypothesis 5b: Psychological capital influences entrepreneurial success through entrepreneurial work engagement and entrepreneurial learning intensity.

\section{Service Orientation and Entrepreneurial Work Engagement}

Service orientation is one of the winning strategies in doing business, especially salient in a services (Oliveira \& Roth 2012; Salanova, Agut \& Peiro 2005). Service orientation is a strategic differentiator which makes the providers' image as unique and special which in turn ensures survivability of service enterprises (Vargo \& Lusch 2008). However, the impact of service orientation on business performance is only realized in long-term (Carraher, Parnell \& Spillan 2009). Nevertheless, one important insight from the service orientation literature is that service oriented entrepreneurs are very passionate in presenting excellence to their customers (Juhdi \& Salleh, 2009; Breugst et al., 2012). Thus, it is assumed that successful entrepreneurs invest energy, time, and focus (entrepreneurial work engagement) in translating their passion towards satisfying customers' desire, needs and wants. Furthermore, another stream of the literature says that service orientation leads to positive behavioral outcome (Lytle \& Timmerman 2006) of which entrepreneurial work engagement is also a positive behavioral outcome (Schaufeli et al. 2006). However, previous research are conducted in Western countries but scarcely in Asian, at least in Malaysia, in which entrepreneurship agenda are very aggressive. Unfortunately, service orientation is relatively new concept in this part of the world (Liu et al. 2003). This is why empirical evidence pertaining to service orientation in business is limited in Asia generally and in Malaysia specifically. Therefore the following hypothesis was tested:

Hypothesis 6: Service orientation is correlated to entrepreneurial work engagement.

\section{Market orientation and Entrepreneurial Learning Intensity}

Market orientation was incorporated in this study to measure entrepreneurs' personal mental attitude towards upgrading knowledge and information about customers, market, and competitors directed at providing excellence (Despandhe \& Farley 1998; Slater \& Narver 2000). For years, customers have been a major emphasis in business practices where firms 
feel obligated to deliver superior quality products and services to customers (Paladino 2007). However, according to Steinman et al. (2000), the paradox is that the more one knows about one's customers, the more one does not know about them because providers' and customers' perceived needs and wants may not match and keep evolving. The mismatch and evolution of customer needs and expectations over time make market orientation not just another trivial concern but it is the key concern for any successful entrepreneur (Jain \& Ali 2013; Slater \& Naver 2000). Market orientation becomes even more critical in services businesses (Slater \& Naver 2000; Sok, O'Cass \& Sok 2013). Thus, the degree of learning intensity about wanting to know what customers need and want and what competition has to offer are expected to depend on the level of market orientation at the personal level of service enterprises.

Hypothesis 7: Market orientation is related to entrepreneurial learning intensity.

\section{Methodology}

\section{Sampling}

The population for this research was among the local entrepreneurs of all races namely the Malay, Chinese, and Indian, who need to be the owners, founders, or top managers of established service SMEs in Malaysia. According to the SSM statistics of companies and business 2013, the overall population of the registered business in Malaysia was 5,215,978 as of the first quarter of 2013. In the year alone, there were 244,495 new business registrations and $90 \%$ were the small and medium enterprises. There were 645,136 small and medium enterprises still in operation since the year 2011 and 591,883 $(91.7 \%)$ were the service SMEs (Economic Census: Profile of Small and Medium Enterprise 2011). The target group of service SME entrepreneurs were taken from the SMI SME Business Directory 2010, an official business directory of SMI Association of Malaysia. It served as the sampling frame for this research to do the simple random sampling. There were 502 registered service SMEs in the directory and they became the population for this study. The services section in the directory lists at least 48 categories of services. There are various types of providers including air express services, beauty salons, cleaning services, computer system consultants, corporate secretarial services, database processing, driving institutes, event management, health care, logistics service providers, packaging, restaurants and catering, training centers, travel agents, tuition centers and more (SMI SME Directory 2010). However, banks and financial services were excluded as this study was concerned because their measurement of success was assumed to be purely financial performance and in fact none of them falls under the small and medium company category by definition. Computer software/hardware developers were also excluded because their rules of the game are patents and innovations (Menell 1998), which were not within the scope of this study. 125 samples were drawn randomly as the study respondents.

For the purpose of this research, "entrepreneurs" was understood as high caliber business owners cum managers (Baron \& Henry 2011; Stokes \& Blackburn 2002) who own and manage any kind of business that is driven by virtue (Mariussen et al. 1997), hold stable financial wealth, and articulate psychological terms of success (Csikzentmihalyi 2003; Haber \& Reichel 2005; Sisodia et al. 2007). With that conceptual definition, this research provided strict compliance to qualify as respondents. Therefore, the entrepreneurs should have all of the following criteria:
a) Formal business registration with the Registration of Companies Malaysia;
b) More than 5 years of experience in managing service business;
c) Business and activities which by nature do not display unethical businesses such as prostitution, gambling, gaming etcetera; and
d) Permanent worker(s) of at least 1.

\section{Measurements}

Entrepreneurial Success. It consists of two domains: financial wealth and psychological measures of performance. The financial wealth domain was adapted from Haber and Reichel's (2005) perceived profitability of the previous, current, and future years with $a=0.92$. An example of the items from Haber and Reichel (2005) is "I perceived high profitability last year". This item was adjusted as "I perceived sufficient income in the first three years of establishment". The psychological performance domain consists of three facets: entrepreneurial satisfaction, feeling of gratitude, and entrepreneurial 
preparedness. Entrepreneurial satisfaction was adapted from Greenhaus's et al. (1990) career satisfaction $(a=0.84)$ with a sample item such as "I am satisfied with the success I have achieved in my career." Feeling of gratitude measures were adopted from McCullough et al. (2002) with a $=0.82$. An example of item is "I have so much in life to be thankful for". Entrepreneurial preparedness measures were adapted from Tang's et al., (2010) evaluation and judgment of opportunities with $a=0.83$. An example of an item is "I can distinguish between profitable opportunities and not-so-profitable opportunities". Altogether 18 items were used to measure entrepreneurial success and they were reviewed by three local entrepreneurs for face and content validity.

Psychological Capital. It was measured using 24 items, adopted from Luthans, Avolio, Avey, and Norman with $a=0.89$ (2007). All four domains were taken together to result in high relationship with outcome as suggested by the literature. An example of an item is "I feel confident analyzing a long-term problem to find a solution".

Entrepreneurial Work Engagement. The work engagement construct has been established in the literature and consists of three dimensions: vigor, dedication, and absorption. There are 17 items and this study made some adaptations on all of them to fit within the study context. The work engagement instrument with an alpha range from $a=0.80$ to $a=0.90$ (Schaufeli et al. 2006) was adapted as entrepreneurial work engagement. An example of an item is "I feel happy when I am working hard enough".

Entrepreneurial Learning Intensity. The development of the item instruments was guided by the organizational learning and entrepreneurial learning literature. A 6-item instrument was taken from Holcomb et al. (2009) since they already assimilate all of the major concerns of previous researchers (e.g., Levitt \& March 1988; Sarasvathy 2004; Politis 2005). A sample items include "I put a great deal to learn business knowledge from direct experience" and "When in lack of knowledge, I have to make exhaustive analysis" (reverse-coded). Two academic experts were sought to review for face and content validity.

Service Orientation. The development of this scale was based on the work of Lytle et al. (1998). From 35 items only 8 items were found to be theoretically applicable to small and medium firms' situation. An example of an item is "I view customers as opportunities to serve rather than as sources of revenue". Two academic experts were sought to review for face and content validity.

Market Orientation. 10 items used to measure market orientation with $a=0.88$ were adapted from Despandhe and Farley (1998), with suggestions from Slater and Narver (2000). An example of an item is "We monitor customers and competitors to find new ways to improve customer satisfaction".

For parsimony of data analysis, all measures usd a 6-point Likert scale ranging from 1 (strongly disagree) to 6 (strongly agree). Two-category response (agree/not agree) with 6 choice-points was used for the purpose of optimizing psychometric sensitivity of the instruments (Cummin \& Gullone 2000). In addition, the 6 choice-points is used because Alwin (1997) and Cummins and Gullone (2000) justify that the greater the number of choice-points, the more reliable, valid, and sensitive the data to capture variance in assessing subjective expressions. The item measurements for entrepreneurial success, psychological capital, entrepreneurial work engagement, entrepreneurial learning intensity, service orientation, and market orientation are presented in APPENDIX A.

\section{Data collection}

Each company's telephone number was contacted to locate the owner-manager, founder, or top manager of the enterprise. An owner-manager means the founder of the enterprise and still manage it until the date of this study. A founder means the original owner who establishes the enterprise. A top manager refers to a trusted employee who is responsible to make routine decisions and to play spoke-person role when necessary in dealing with customers and clients. Through the personal assistance of the enterprise, the researchers set an appointment with the owner-manager, founder, or top manager to meet. In cases where the owner-managers, founders, or top managers did not have any personal assistance, the researchers telephoned them directly to affirm their availability to meet and to inform about the research interests, for the purpose of completing the questionnaire face-to-face. However, in many instances, the respondents requested answering the questionnaire via mobile phone because it was more convenient for most of them. There were occasions 
where the respondents requested the researchers to call back at other times. The questionnaire survey with 83 items was completed within 30 minutes in average for face-to-face survey. However, it was prolonged to about one hour and a half via phone.

\section{Analysis and results}

The raw data was entered, cleaned, and transformed based on the six variables. SPSS 20 was employed to do the basic statistical analysis. As a start, the basic quantitative and descriptive statistics were computed to estimate the central tendency of the research sample. Another basic data analysis is scale reliability analysis to evaluate the internal consistency of measurements (Cronbach 1951). After the data was confirmed clean and free from any outlier and missing data, then normality, linearity and homoscedasticity were checked. Grounded in multivariate statistics approach due to the number and types of relationships to be analyzed in this study, all those multivariate assumptions were necessary to be deliberated. The assumptions of normality, linearity and homoscedasticity were addressed following the technical suggestions by Hair, Anderson, Tatham and Black (1998) and Tabachnick and Fidell (2001) and they were met.

A paired sample t-test was then used to check for non-response bias. Non-response bias is always possible in crosssectional survey where the data come from the same group and yet they somehow could come from two different conditions (more ready respondents and less-ready respondents). The t-value, degree of freedom, and two-tail significance can tell the degree of difference between the groups (Coakes \& Steed 2007). If they are found to be no significant difference, there should be no serious issue of non-response bias (Breaugst et al. 2011).With 42 non-respondents out of 125 targeted sample of respondents, this study was concerned about their impacts on the study findings and interpretations especially when it comes to generalizing the findings. According to Amstrong and Overton (1977), the impact of non-responses can be estimated and it can be minimized. A common way is by using time-trend extrapolation (Amstrong \& Overton 1977; Breaugst et al. 2011; Idar \& Mahmood 2011). The extrapolation is based on the assumption that the samples which are "less ready" are almost like the non-respondents (Amstrong \& Overton 1977). Accordingly, the current study identified the "less ready" ad "more ready" respondents. In the data base, there were 21 "less ready" respondents (who requested the researcher to call back). Then, the responses of these "less ready" samples were entered as an additional variable in the SPSS data file and compared to that of the first 21 respondents in the same file (whom were assumed to be "more ready"). With these two groups, paired sample t-test was run to examine differences in terms of key constructs such as psychological capital, service orientation, market orientation, entrepreneurial work engagement and entrepreneurial learning intensity as well as of several demographic variables. All of the results were found to be non-significant, indicating that there were no significant difference between the groups. Thus, non-response bias was unlikely to be a concern of this research.

A factor analysis is useful to address issues such as common method variance bias, multicollinearity, and convergent/discriminant validity. Common method variance bias can be assessed by calculating variance proportion (Ramayah, Yan \& Sulaiman 2005). If the variance proportion score is less than 0.5 , there should be no serious issue of common method variance bias. Multicollinearity could cause statistical problems and weaken statistical analysis but it is not uncommon in behavioral studies. It is when variables are highly correlated (Byrne 2001; Tabachnick \& Fidell 2001). In SPSS 20 through collinearity diagnostics, data across variables and in-rows should show no variable has more than one variance proportion greater than .50 (Tabachnick \& Fidell 2001, pg 98). A correlation analysis was completed to explore the bivariate relations among the constructs. All variables were positively correlated at significant level of 0.01 or 0.05 (2tailed). However, certain variables had alarmingly high correlation coefficients (Tabachnick \& Fidell 2001) close to 0.80 although not reaching 0.90 . In particular, the possibility of multicollinearity between entrepreneurial work engagement and psychological capital seemed to exist as their correlation matrix was $0.799(p<.01)$. As such, multicollinearity could occur and should be given attention because multicollinearity could cause logical and statistical problems and also it could weaken the statistical analysis (Byrne 2001; Tabachnick \& Fidell 2001).

Therefore, a statistical test on collinearity was done to assess the goodness-of-fit analysis on entrepreneurial work engagement and psychological capital. If goodness-of-fit indices ( $\mathrm{X}^{2} / \mathrm{df}$ ) are less than 5 , there is probably no problem of multicollinearity (MacCallum 1998; Byrne 2001). The chi-square tests in SPSS for entrepreneurial work engagement yielded a goodness fit of $X^{2}=32.55$ and $X^{2} / \mathrm{df}=1.48$. Similarly, psychological capital yielded a goodness fit of $X^{2}=49.31$ and $X^{2} / \mathrm{df}$ $=1.49$. Therefore, both constructs fit the data. In other words, there was no serious problem of multicollinearity and thus both constructs could be used in the subsequent hypothesis testing. 
Two important components of construct validity are convergent and discriminant validity which are a concern in this study. Convergent validity is the degree to which measures of a construct that theoretically should be related are related. Discriminant validity is the degree to which measures of a construct that theoretically should be unique are not overlapping. Both can be identified by analyzing the factor loadings and cross loadings in the factor analysis (Fornell \& Larcker 1981; Ramayah, Yan \& Sulaiman 2005).

Convergent validity can be identified in the loadings and cross loadings of all the 83 item instruments. In the factor analysis, the loadings and cross loadings showed that all six constructs had convergent validity. The highest scores down and across the loadings table belonged to the according variables, except item 10 and 15 of psychological capital of which the highest loading for both fell into entrepreneurial work engagement. The scores of loadings and cross loadings are available in APPENDIX B. To solve this problem, discriminant validity was assessed. As SPSS 20 does not provide the average variance extracted (AVE), the calculation of the AVE data of each six variables was done manually following the procedure proposed by Fornell and Larcker (1981) and Ramayah et al. (2005). The calculation for the AVE is as follow:

\section{$\mathrm{AVE}=\frac{R S L}{R S L+E S L}$}

[RSL: cumulative \% rotation sums of squared loadings; ESL: cumulative \% extraction sums of squared loadings]

Table 1 presents the AVE (in bold) and the squared correlations of all six variables. According to Fornell and Larcker (1981), the AVE of a variable should be higher than the squared correlations between the variable and all other variables. It was found that psychological capital and entrepreneurial work engagement did not have discriminant validity initially. It could be because of the items 10 and 15 of psychological capital. The researchers decided to delete item 10 about optimism (Right now I see myself as being pretty successful at work) which conceptually overlapped with pride in entrepreneurial work engagement; and item 15 about resilience (I can be on my own, so to speak, at work if I have to) which overlapped with dedication in entrepreneurial work engagement. After the deletions, the Pearson's Correlation Product Moment was run and the correlation between psychological capital and entrepreneurial work engagement was .754 (down from .799) and thus the squared correlation was .569 (down from .638). After the adjustment, these variables were appropriately to be included in the main analysis and hypotheses testing.

Table 1: Discriminant validity of constructs

\begin{tabular}{lllllll}
\hline Constructs & 1 & 2 & 3 & 4 & 5 & 6
\end{tabular}

\begin{tabular}{lllllll}
\hline ENTSS & .673 & & & & & \\
EWE & .552 & .573 & & & & \\
ELI & .461 & .545 & .581 & & & \\
PSYCAP & .590 & .569 & .469 & .627 & & \\
SO & .165 & .141 & .169 & .194 & .560 & \\
MO & .101 & .109 & .091 & .159 & .383 & .584 \\
\hline
\end{tabular}

(Diagonals (in bold) represent the AVE and the other scores are the squared correlations.)

(ENTSS - entrepreneurial success; EWE - entrepreneurial work engagement; ELI - entrepreneurial learning intensity; PSYCAP - psychological capital; SO - service orientation; MO - market orientation) 
This research was a cross-sectional survey for which the measures of both independent and dependent variables all depended on single-source reporting. Therefore, a common method variance bias is always a possibility (Johnson et al. 2011; Summers 2001). According to Ramayah et al. (2005) almost a similar technique for multicollinearity in Tabachnick and Fidell (2001) can be employed to test for common method variance bias by calculating the variance explained proportion (the ratio between initial eigenvalues cumulative rate and extraction sums of squared loadings cumulative rate). The variance proportion score should be less than 0.50 (Tabachnick \& Fidell 2001, pg. 98) to claim that there is no serious issue of common method variance bias (Ramayah et al. 2005). Using factor analysis under dimension reduction in SPSS 20, correlation matrix and promax rotation, all 83 items had eigenvalues greater than 1, and the test score showed that common method variance bias was not a serious problem in this study. The variance proportion was calculated manually following Ramayah et al. (2005) and the result was 0.29 . The calculation is as follow:

Common Method Variance $\quad=\frac{\text { cummulative } \% \text { extraction sums of } s \text { quared loadings }}{\text { cummulative } \% \text { initial eigenvalues }}$
$=81.741 \div 23.393$
$=0.29 \quad$ (less than 0.50$)$

\section{Demographics}

Of the 83 respondents, the majority were founders $(74.7 \%)$ and still being the owners and top managers of their according companies to the date of this study. There were $57(68.67 \%)$ males and $26(31.32 \%)$ females. Among them only $5(6 \%)$ were aged more than $60 ; 23(27.7 \%)$ aged between 28 and 39 years; and 55 or majority (62.7\%) were aged between 40 to 59 years. 50 out of $83(60.2 \%)$ respondents had obtained entrepreneurial experience of more than 10 years in entrepreneurial service ventures. $20(24 \%)$ of them had 5 to 9 years of experience, while the rest $13(15.7 \%)$ had about 5 years of experience. In average, service SME entrepreneurs in Malaysia had 22 employees.

\section{Descriptive statistics}

Table 2 presents the descriptive statistics. The findings indicated that the data points tend to be close to the data means, which in turn indicated that the constructs being tested were theoretically and appropriately measuring what they were supposed to measure. Most of the respondents perceived that they were successful (mean $=5.07$ ). Similarly, based on the descriptive statistics, the entrepreneurs perceived that they had moderately high level of entrepreneurial work engagement (mean $=5.50)$, psychological capital (mean $=5.18)$, and entrepreneurial learning intensity (mean $=4.98)$. They also perceived that they had considerable concern about the customers, market, and competitors. The mean were 4.79 for market orientation and 4.77 for service orientation.

Table 2: Variables, Means and Standard Deviations

\begin{tabular}{lllll}
\hline & Min. & Max. & Mean & Std. Deviation \\
Entrepreneurial Success & 4.11 & 5.89 & 5.073 & .393 \\
Entrepreneurial Work Engagement & 4.65 & 6.00 & 5.498 & .375 \\
Entrepreneurial Learning Intensity & 3.83 & 6.00 & 4.975 & .549 \\
& & & & \\
Psychological capital & 3.79 & 6.00 & 5.180 & .391 \\
Market Orientation & 3.00 & 6.00 & 4.792 & .642 \\
Service Orientation & 3.00 & 6.00 & 4.768 & .618 \\
\hline
\end{tabular}




\section{Reliability}

Reliability test was run to check the internal consistency of the constructs (Cronbach 1951) and to check that all measurements were free of unstable errors (Cooper \& Emory 1995). The results showed that each construct scored an acceptable standard reliability coefficient alpha (Cronbach 1951; Peterson 1994). The reliability and validity results are presented in Table 3. Even though entrepreneurial learning intensity had a Cronbach alpha of 0.694 , which is less than the average of 0.77 in psychology research (Peterson 1994), it does not necessarily imply a problem of internal consistency (Yang \& Green 2011). The relatively low score could be due to the scale length (Yang \& Green 2011) which was only 6 items in the case of entrepreneurial learning intensity in this study. The alpha of 0.694 is still very close to 0.7 to remain within the acceptable range for further analysis (Nunnally, 1978; Peterson 2004).

Table 3: Reliability of constructs

\begin{tabular}{|c|c|c|c|}
\hline Constructs (domains) & & Number of items & $\begin{array}{l}\text { Cronbach's alpha } \\
\text { (in earlier pretesting) }\end{array}$ \\
\hline Entrepreneurial success & $\begin{array}{ll}\text { - } & \text { Financial } \\
\text { wealth } & \\
\text { - } & \text { Psychological } \\
\text { performance }\end{array}$ & $\begin{array}{l}3 \\
15\end{array}$ & $\begin{array}{l}.680(.691) \\
.855(.872) \\
\\
\text { overall .855 (.857) }\end{array}$ \\
\hline $\begin{array}{l}\text { Entrepreneurial work } \\
\text { engagement }\end{array}$ & - & 17 & $.915(.933)$ \\
\hline $\begin{array}{l}\text { Entrepreneurial learning } \\
\text { intensity }\end{array}$ & - & 6 & $.694(.601)$ \\
\hline Psychological capital & - & 24 & $.894(.913)$ \\
\hline Service orientation & - & 8 & $.840(.830)$ \\
\hline Market orientation & - & 10 & $.865(.840)$ \\
\hline
\end{tabular}

\section{Multiple-Mediation Hypothesis Model Testing}

SPSS Macro was used to test the multiple-mediation hypotheses. The results are shown in Figure 1.

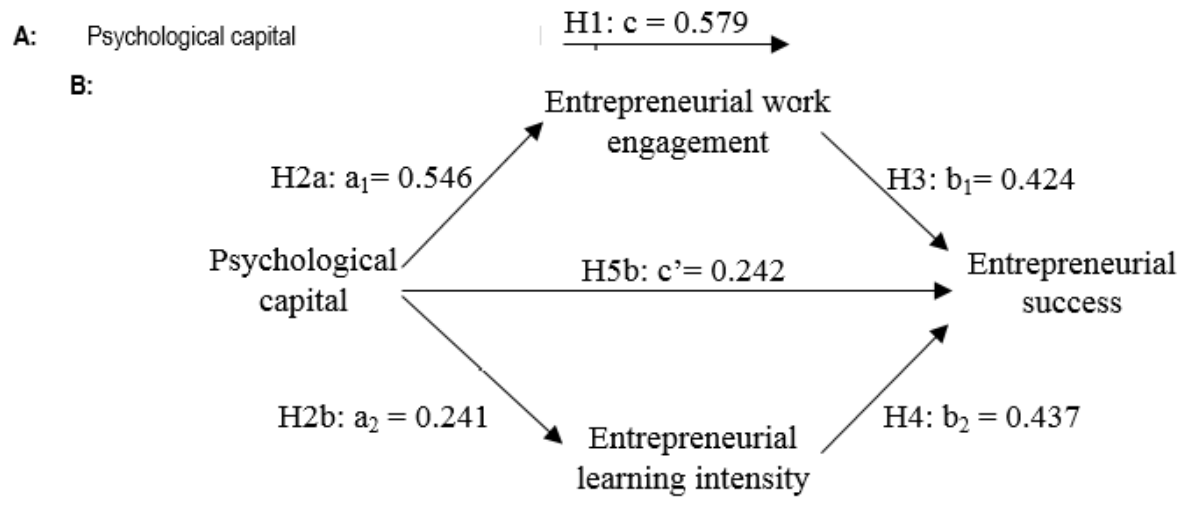

Figure 1: Illustrations of Multiple Mediation Effects 
The procedures in SPSS Macro involved testing mediation effects by entrepreneurial work engagement and entrepreneurial learning intensity (the multiple mediators) simultaneously. The investigations involved three parts:

(1) Investigating the total indirect effect of the predictor (psychological capital) on the dependent variable (entrepreneurial success) through the mediators (entrepreneurial work engagement and entrepreneurial work engagement);

(2) Investigating the specific indirect effect of psychological capital on entrepreneurial success through entrepreneurial work engagement; and

(3) Investigating the specific indirect effect of psychological capital on entrepreneurial success through entrepreneurial learning intensity.

The total effect (c) in A (Figure 1) of psychological capital on entrepreneurial success was examined. As expected, psychological capital was strongly related to entrepreneurial success $(\beta=0.579, p<0.000)$. Hypothesis 1 was supported. The specific indirect effect in B (Figure 1) of psychological capital and entrepreneurial success via mediators was defined as the product of two unstandardized paths $\left(a_{1} b_{1} ; a_{2} b_{2}\right)$ linking psychological capital to entrepreneurial success via those mediators. Then, it becomes necessary for the predictor (psychological capital) to have significant influence on each of the mediators (entrepreneurial work engagement and entrepreneurial learning intensity). The findings showed that psychological capital had significant direct effects on entrepreneurial work engagement ( $a_{1}$ path: $\beta=0.546, p<0.000$ ) and on entrepreneurial learning intensity ( $a_{2}$ path: $\beta=0.241, p<0.000$ ). Therefore, hypotheses $2 a$ and $2 b$ were supported.

Findings showed that entrepreneurial work engagement had a significant effect on entrepreneurial success ( $b_{1}$ path; $\beta=$ $0.424, p<0.0468$ ). Hypothesis 3 was supported. Similarly, entrepreneurial learning intensity had significant direct effect on entrepreneurial success ( $b_{2}$ path; $\beta=0.437, p<0.0409$ ). Hypothesis 4 was supported.

The findings showed that the specific indirect effect of psychological capital on entrepreneurial success via entrepreneurial work engagement was 0.232 (i.e. $0.546 \times 0.424$ ); and via entrepreneurial learning intensity was 0.105 (i.e. $0.241 \times 0.437$ ). The Pearson's correlation of the mediators was not an issue in this study since both variables were positively correlated: $\beta$ $=0.610, p<0.01$. Hypothesis 5 a was supported.

The total indirect effect is the sum of the specific indirect effects. Thus, the total indirect effect was 0.337 (i.e. $0.232+$ 0.105). Alternatively, the total indirect effect of psychological capital on entrepreneurial success through both mediators was the difference between total effect and direct effect of psychological capital on entrepreneurial success or $c-c^{\prime}=.579$ $-.242=.337$. However, the study is yet to confirm the significance of this total indirect effect of the mediators.

Bootstrapping is the best method to confirm the significance of the multiple-mediation effects (0.337) (Duffy et al. 2012; Kim \& Park 2009) because it overcomes the potential problems caused by unmet assumptions of multiple-mediation theory (Preacher \& Hayes 2008). Bootstrapping is also the best to test the significance of the total indirect effects associated with each mediator (Zhao, Lynch \& Chen 2010). Within the application of SPSS Macro, this researcher created 5,000 bootstrap samples at $95 \%$ confidence interval by taking into accounts the bias corrected and computed for the upper and lower potential limits of the indirect effects. Across the 5,000 bootstrap samples, if there is no zero value then the indirect effects would be significant. The findings showed that entrepreneurial work engagement and entrepreneurial learning intensity were significant mediators when confidence intervals did not contain a zero (see Table 4). Hypothesis $5 \mathrm{~b}$ was supported. Somewhat more fundamental in the findings was that entrepreneurial work engagement had slightly stronger statistical magnitude (specific indirect effect $=.232$ ) as a competing mediator at significant level compared to entrepreneurial learning intensity.

Table 4: Bootstrap Results for Specific and Total Indirect Effects

\begin{tabular}{llll}
\hline Mediators & $\begin{array}{l}\text { Bootstrap } \\
\text { estimate }\end{array}$ & se & $\begin{array}{l}\text { Bias corrected and accelerated 95\% } \\
\text { confidence interval }\end{array}$ \\
\cline { 3 - 5 } & & Lower & Upper \\
\hline
\end{tabular}




\begin{tabular}{lcccc}
\hline $\begin{array}{l}\text { Entrepreneurial work } \\
\text { engagement (specific) }\end{array}$ & .232 & .057 & .0121 & .2841 \\
$\begin{array}{l}\text { Entrepreneurial learning } \\
\text { intensity (specific) }\end{array}$ & .105 & .054 & .0109 & .2179 \\
\begin{tabular}{l} 
Total indirect effect \\
\hline
\end{tabular} & .337 & .081 & .0796 & .3989 \\
\hline
\end{tabular}

The summary of the multiple-mediation hypothesis testing model shows moderately high percentage of contribution to the variance of entrepreneurial success $\left(R^{2}=0.639 ; p<0.000\right)$. In other words, $63.9 \%$ of entrepreneurial success was explained by psychological capital through entrepreneurial work engagement and entrepreneurial learning intensity. Overall, the multiple-mediation hypotheses were all supported.

\section{Service Orientation and Entrepreneurial Work Engagement}

Hypothesis 6 was drawn on the basis that entrepreneurs are concern about the excellence of service delivery (service orientation). They show concern by dedication and passion on the business (entrepreneurial work engagement). A Pearson's product moment correlation analysis resulted in positive and significant relationship between service orientation and entrepreneurial work engagement $(\beta=.338 ; p<0.01)$. Therefore, Hypothesis 6 was supported.

\section{Market Orientation and Entrepreneurial Learning Intensity}

Hypothesis 7 was drawn on the basis that the higher the entrepreneurs' stance in understanding customers, market, and competition (market orientation), the higher the entrepreneurs' efforts to know further by acquiring, organizing, and capitalizing the new knowledge into decision making to exploit opportunities (entrepreneurial learning intensity). A simple regression in SPSS 20 resulted in non-significant relationship between market orientation and entrepreneurial learning intensity. Therefore, Hypothesis 7 was not supported. Table 5 presents the findings.

Table 5 Market Orientation and Entrepreneurial Learning Intensity

\begin{tabular}{lllllll}
\hline IV & $\begin{array}{l}\text { Unstand. } \\
\text { Beta }\end{array}$ & $\begin{array}{l}\text { Stand. T } \\
\text { Beta }\end{array}$ & Sig. & 95.0\% Confidence Interval \\
& & & & Lower Bound & Upper Bound \\
\hline (Constant) & 3.514 & & .560 & .577 & -.812 & 1.367 \\
MO & .121 & .139 & 1.544 & .126 & -.035 & 2.481 \\
(MO: market orientation) & & & & &
\end{tabular}

In summary, the multiple-mediation hypotheses were supported, showing that statistically and empirically this study has enriched the body of knowledge of entrepreneurship. Entrepreneurial success can be well explained by psychological capital and the explanation was further enhanced by entrepreneurial work engagement and entrepreneurial learning intensity simultaneously. In this study, the role of marketing in entrepreneurship is no more a matter of debate but some findings about market orientation in this study could not show support.

\section{Discussion and conclusion}

\section{Psychological capital and entrepreneurial success: A multiple-mediated relationship}

The findings of this study have supported the proposition that psychological capital is positively related to entrepreneurial success. Such finding is consistent with prior studies which assert that psychological capital is one of critical personal resources required by entrepreneurs (Avey et al. 2010; Luthans et al. 2005) especially in uncertain environment. The 
finding also confirms that self-efficacy, optimism, resilience, and hope (four elements of psychological capital) must be taken together as a package of valuable personal assets and four of them are not options to have or not to have, as claimed and strongly suggested by the founding authors (i.e. Luthans, Luthans \& Luthans 2004). For example, it is not enough to have just self-efficacy in entrepreneurial venturing because entrepreneurial venture is so rough and unpredictable that requires clearer achievement motive (Poon et al 2006), market change awareness (Idar \& Mahmood 2011), and resilience (Luthans \& Youssef 2007). Taken together those four elements conceptualized as psychological capital is theoretically an indicator of personal strength or valuable resources (Carr 2011). This study finding is also in line with prior studies (Hmieleski \& Carr 2007; Peterson et al. 2011; Sweetman et al. 2011) which argue that positive psychological capital could determine entrepreneurial success.

Therefore, this study supported the resource-based view which asserts that unique and rare resources, including psychological resources are the key determinants of entrepreneurial success of service SME owner-managers. That is, when entrepreneurs have high psychological capital they are likely able to take all necessary positive actions (strategies) such as engagement in entrepreneurial work (entrepreneurial work engagement) and strong willingness to learn new knowledge (entrepreneurial learning intensity) even during rough times. On the other hand, those who lack of psychological capital would not be able to endure rough experiences and would gradually withdraw (Carr 2011; Seligman et al. 2005). That being said, this study enriches entrepreneurship theory by introducing the importance of psychological capital besides the acceptance of personality trait importance in entrepreneurship theory. In other words, the findings in this study show some support to the notion which says entrepreneurs are born with some unique characteristics. However practically, entrepreneurs pursuing success must have high level of psychological states and could still learn to develop strong level of self-efficacy, optimism, resilience and hope, while these personal assets can be cultivated (Luthans \& Youssef 2007).

The proposed comprehensive predictor and multiple-mediators research framework was able to explain the major variances in entrepreneurial success $(63.9 \%)$. It means that $63.9 \%$ of the variance in entrepreneurial success is majorly explained by psychological capital, entrepreneurial work engagement, and entrepreneurial learning intensity. The findings were consistent with the propositions of previous research in entrepreneurship (e.g., Haber \& Reichel 2005; Rauch \& Frese 2000) which specify the power of having positive mental and emotions and strategies on the way to earn meaningful achievements or entrepreneurial success.

The findings of this study indicate that psychological capital predicts entrepreneurial success directly and indirectly through both entrepreneurial work engagement and entrepreneurial learning intensity. Such findings are also consistent with Rauch and Frese's (2000) claim that some mediation mechanisms should be engaged in order to understand entrepreneurial success phenomenon. It is because the nature of entrepreneurial success is very complex of which investigation of direct relationship only would not suffice (Simpson et al. 2012). Furthermore, this study found that not only both entrepreneurial work engagement and entrepreneurial learning intensity were significant multiple-mediators but also entrepreneurial work engagement actually had a bigger effect size on the relationship between psychological capital and entrepreneurial success.

Therefore, theoretically and empirically this study has supported the notion of training and motivating entrepreneurs to instill strong psychological states of mind and substantial effort, namely higher entrepreneurial work engagement, and entrepreneurial learning intensity, to ensure entrepreneurial success (Hmieleski \& Carr 2007). This study confirms the main assumption of positive psychology which states that positive action lead to positive outcome. This study also shows support to the argument that says entrepreneurs who have positive psychological states would be more successful and benevolent to the society at large for longer terms (Csikszentmihalyi 2003; Sisodia et al. 2007). In other words, entrepreneurs who want to be successful should have the critical resources, i.e. psychological capital in addition to monetary capital. These psychological resources need to be transmitted into physical, mental and emotional actions or strategies to ensure ultimate entrepreneurial success (Baron \& Henry, 2011; Csikszentmihalyi 2003; Seligman 2000).

\section{Service and market orientations as firm strategies}

Marketing concepts such as service and market orientation are very crucial in the survivability and sustainability of businesses of any kind and even more critical in service enterprises (Salanova et al. 2005; Slater \& Naver 2000; Zheng \& Yin 2010). However, this study only found support for service orientation which is correlated with entrepreneurial work engagement. 
Service orientation was positively and significantly correlated with entrepreneurial work engagement. The findings of this study were consistent with prior studies which specify that service orientation acts as a differentiating strategy between high and low service performance (e.g, Vargo \& Lusch 2008). The finding of this study had proven statistically that service orientation could have marginal explanation on entrepreneurial work engagement. The finding is consistent with Lytle and Timmerman (2006) which found that service orientation leads to positive behavioral outcome. It means that service orientation could be as another translation of serious efforts in ensuring customers' needs and wants being fulfilled excellently. The explanation of such finding is also found in previous research which states that good service orientation is reflected during service encounters where both the producer and customers meet. During the service encounters, the feeling of delight and happiness of the customers become dedication of the producer to engage further in providing excellent services. In other words, by applying marketing concepts such as service orientation the producer in return becomes more able to present memorable services with dedication, enthusiasm, and passion.

The relationship between market orientation and entrepreneurial learning intensity was not significant based on the collected data. The underlying premise of market orientation concept being examined within this research framework initially was to indicate that its adoption would constitute a good strategy that can benefit entrepreneurs directly or indirectly. However, market orientation, in this study, could not explain why entrepreneurs would engage in serious learning (entrepreneurial learning intensity) by channeling their mind and hearts closely to customers, market, and competitors. There are two plausible explanations. First, market orientation might be more relevant to large firm than service SMEs, the context of this study (Steinman et al. 2000; Zheng \& Yin 2010). In a meta-analysis involving fifty-three (53) empirical studies representing an overall sample size of 12,043 respondents from 23 countries, across five continents, it is found that market orientation is effectively practiced by multinational corporations with substantial financial, technical, management and marketing capabilities (Cano, Carilla \& Jaramillo 2004); whereas service SMEs would have less resources to perform specific tasks looking at market orientation (Jain \& Ali 2013).

Second, integration of market orientation in entrepreneurial success study is still new and requires more researches. In the literature, there are mixed results. For example, Kirca et al. (2005) has shown in a meta-analysis study that market orientation - outcomes relationship would be lower or may not be significant in service firms compared to that in manufacturing companies. Similarly, Steinman et al. (2000) highlight that the more information entrepreneurs know about customers and market the less information which match. In practice, market orientation efforts such as making surveys, focus group discussions and research and development involving customers are quite costly (Svendsen et al. 2011) where majority of small and medium sized enterprises could not afford.

\section{Implications of study}

This study provides theoretical, methodological and practical implication. In terms of entrepreneurship and small business theoretical implication, it was evident that entrepreneurial success among small and medium service enterprises (service SMEs) should be conceptualized with reference to resource-based view, small business success and positive psychology theories. From the resource-based view, the concept of "resources" should be broadly defined to include tangible (financial and material resources) and intangible (human and psychological capital) resources. Psychological capital should be viewed as key resources within SMEs, especially service SMEs. One way of explaining, psychological capital also play significant role in ensuring the venturous efforts heading towards entrepreneurial success. Resources would produce better outcome if properly translated into positive actions and strategies that cover formal strategy such as service orientation and entrepreneurial strategies such as entrepreneurial work engagement and entrepreneurial learning intensity. Ultimately, positive outcome or entrepreneurial success is the function of these valuable resources and positive action (strategies).

The theoretical sequencing proposition of resource, strategies and success within small business success model; and the proposition which stated that positive actions produce positive outcomes in positive psychology theory are meaningful in explaining entrepreneurial success and its antecedents. Strategies as mediator should receive more attention, especially entrepreneurial strategies that refer to intangible efforts by entrepreneurs in terms of entrepreneurial work engagement and learning intensity. This finding also implies that future research in entrepreneurial success should integrate theories by examining more variables using multiple intervening frameworks. This study is among the pioneer research proposing complex mediating relationships in the entrepreneurship literature and answering the notion that entrepreneurial success is a complex outcome variable which requires a comprehensive explanation (Baron \& Henry, 2011). 
The methodological implication is that future entrepreneurship studies require a robust statistical analysis (Rauch \& Frese 2000). Employing a multiple-mediation model hypothesis testing, this study has provided methodologically evidence that entrepreneurial success is partly an attribution of psychological capital on entrepreneurial success mediated by entrepreneurial work engagement, and entrepreneurial learning intensity. The multiple-mediation analysis method also allows further diagnostic of a stronger mediator, in this case, entrepreneurial work engagement had slightly stronger statistical magnitude, which means the stronger mediator in this study.

The practical implication of this study is on entrepreneurs and potential entrepreneurs. Based on the findings of this study, entrepreneurs are expected to be equipped with strong psychological states of mind by having self-efficacy, optimism, resilience, and hope. They are also expected to be more engaged in their entrepreneurial venture and spending more time on high-learning to ensure success. Nonetheless, they must be aware that entrepreneurial success could be indicated by financial and psychological measures. Perhaps having sense of entrepreneurial satisfaction, feeling of gratitude, and preparedness is more real in surviving the cuts of entrepreneurial venturing. To policy makers, this study provided guidelines useful to prioritize potential entrepreneurship training and incentives. Entrepreneurship training should also cover psychological capital components and strategies. In particular, entrepreneurs with significant work engagement and learning intensity should be given more attention and service orientation as part of the firm strategies should be included in training programs for potential entrepreneurs, especially training design for the service SMEs.

\section{Limitations and future research suggestions}

Although the research was designed carefully, it was not without limitations. The limitations have to be highlighted to caution against straight forward interpretations of the research findings and to give directions for future research. First, the data collection method was cross-sectional. The data was gathered at one time by which could not represent the actual picture of how entrepreneurial success actually evolves within the mind of entrepreneurs in the real sense. Therefore, this study could not establish causality inference from the data. If the data were collected using longitudinal method, the study could carefully describe the development from being potential entrepreneurs, to early start-ups, and to established entrepreneurs.

Second, in order to examine the extent of entrepreneurial learning intensity impacting on psychological performance, qualitative methods like case studies could have been more useful to study the differences between risk-takers (usually have high entrepreneurial learning intensity) and risk-averse (usually have low entrepreneurial learning intensity). The results would turn out to be more rigorous because case studies could explain why, when and how an entrepreneur gradually transforms to become an established entrepreneur due to entrepreneurial learning intensity in real time.

Third, the context of the study was focused on established entrepreneurs of small and medium service enterprises in Malaysia. Thus, future research could include established entrepreneurs in other industrial sectors such as agriculture, food and beverages, and manufacturing. The logic is for making comparison and comprehensive conclusions pertaining to the true essence of entrepreneurial success and the contributing factors. Perhaps variations will be discovered, given the differences. It would be interesting to discover in which disciplines that psychological states particularly psychological capital and its related strategies have the most impact from the entrepreneurs' perspective.

Last but not least, the sample size is another limitation. The usable size sample (83) was hindering advantages of using more robust statistical software such as structural model equation (SEM) which requires normally a sample of at least 200 respondents (Hair et al. 1998), considering the number of relationships and parameters in the research model. For example, even though the R-squared value of the multiple-mediation model was more than 60 percent (63.92\%), the significance of the goodness fit indices of the model could not be tested. Hence, future research should replicate this study using a larger sample size.

\section{Conclusion}

To conclude, this study confirmed theoretically and statistically that psychological capital is the most critical personal psychological resource for all small and medium-sized enterprise owners to have the chance to become successful entrepreneurs. This means the inclusiveness of psychological states variables, such as positive psychological capital, would enhance the understanding of entrepreneurial success, in line with the propositions by previous scholars who posited that the higher the personal psychological resources, the higher chance for entrepreneurs to earn lasting entrepreneurial 
success. Of course, the explanation of entrepreneurial success is not simplistic. This study substantiates that it would be more comprehensive when a couple of mediators are introduced to explain entrepreneurial success because entrepreneurial success is a complex phenomenon. The significant relationship between psychological capital (predicting variable) and entrepreneurial success (dependent variable) necessitates this study to examine mediation mechanisms between psychological capital and entrepreneurial success. Entrepreneurial work engagement and entrepreneurial learning intensity, as mediators, both were the intervening variables that strengthen the influence of psychological capital on entrepreneurial success significantly. Previous research urge entrepreneurs of small and medium-sized enterprises to be real and closer to market, customers, and competitors. Therefore, service and market orientation are newly introduced variables in this study to seek potential enriching explanation. Although the effect of market orientation remain unanswered, service orientation was found to be related to entrepreneurial work engagement in service SMEs context. Finally, future research involving service companies should examine the role of service orientation in more depth because it might be related to service firm success and long-term sustainability.

\section{References}

[1] Alstete, J.W. 2008. Aspects of entrepreneurial success. Journal of Small Business and Enterprise Development 15(3): 584-594.

[2] Alwin, D.F. 1997. Feeling thermometers versus 7-point scales. Sociological Methods \& Research 25(3): 318-340.

[3] Amstrong, J.S. \& Overton, T.S. 1977. Estimating non-response bias in mail survey. Journal of Marketing Research 14: 396-402.

[4] Anderson, L.M., Giacalone, R.A. \& Jurkiewicz, C.L. 2007. On relationship of hope and gratitude to corporate social responsibility. Journal of Business Ethics 70(4): 401-409.

[5] Artinger, S. \& Powell, T.C. 2015. Entrepreneurial failure: Statistical and psychological explanations. Strategic Management Journal doi: $10.1002 / \mathrm{smj} 2378$.

[6] Avey, J.B., Luthans, F., Smith, R.M. \& Palmer, N.F. 2010. Impact of positive psychological capital on employee wellbeing over time. Journal of Occupational Health Psychology 15(1): 17-28.

[7] Baron, R.A. \& Henry, Rebecca A. 2011. Entrepreneurship: The genesis of organizations. APA Handbook of Industrial and Organizational Psychology, pp. 241-273. Washington, DC. USA. doi:10.1037/12169-008.

[8] Breugst, N., Domurath, A., Patzelt, H. \& Klaukien, A. 2012. Perceptions of entrepreneurial passion and employees' commitment to entrepreneurial ventures. Entrepreneurship Theory and Practice doi:10.1111/j.1540-6520.

[9] Byrne, B.M. 2001. Structural equation modeling with Amos: Basic concepts, applications, and programming. Lawrence Erlbaum Associates, Mahwah, New Jersey, USA.

[10] Cano, C.R., Carilla, F.A. \& Jaramillo, F. 2004. A meta-analysis of the relationship between market orientation and business performance: Evidence from five continents. International Journal of Research in Marketing 21(2): 179-200.

[11] Carr, A. 2011. Positive psychology: The science of happiness and human strengths. 2nd edition. Routledge, New York.

[12] Carraher, S., Parnell, J.A. \& Spillan, J.E. 2009. Customer service orientation of small retail business owners in Austria, The Chech Republic, Hungary, Latvia, Slovaskia, and Slovenia. Baltic Journal of Management 4(3): 251268.

[13] Cavana, R.Y., Delahaye, B.L. \& Sekaran, U. 2001. Applied Business Research: Qualitative and Quantitative Methods. John Wiley \& Sons. Australia.

[14] Coakes, S.J. \& Steed, L. 2007. SPSS for Windows analysis without anguish. John Wiley \& Sons, Australia.

[15] Cooper, D.R. \& Emory, W.C. 1995. Business Research Methods. 5th edition. Richard D. Irwin, Inc. USA.

[16] Cope, J. 2003. Entrepreneurial learning and reflection: Discontinuous events as triggers for "higher level learning". Management Learning 34(4): 429-450.

[17] Cronbach, L.J. 1951. Coefficient alpha and the internal structure of tests. Psychometrika 16(3): 297-334.

[18] Csikzentmihalyi, M. 2003. Good Business: Leadership, Flow, and The Making of Meaning. Penguin Group, New York. 
[19] Culbertson, S.S., Fullagar, CJ. \& Mills, M.J. 2010. Feeling good and doing great: The relationship between psychological capital and well-being. Journal of Occupational Health Psychology 15(4): 421-433.

[20] Cummins, R.A. \& Gullone, E. 2000. Why we should not use 5-point Likert scale: The case for subjective quality life measures. Proceedings in Second International Conference on Quality of Life in Cities, Singapore: National University of Singapore.

[21] Davidsson, P. 2005. Interpreting performance in small business research. In Proceedings Strathclyde Entrepreneurship Research Workshop, Leeds. UK. Available at http://eprints.qut.edu.au.

[22] Despandhe, R. \& Farley, J.U. 1998. Measuring market orientation: Generalization and synthesis. Journal of Market Focused Management 2: 213-232.

[23] Dutton, J.M., Thomas, A. \& Buttler, J.E. 1984. The history of progress functions as a managerial technology. The Business History Review 58(2): 203-233.

[24] Economic Census: Profile of Small Medium Enterprise (Malaysia) 2011

[25] Fisher, R., Maritz, A. \& Lobo, A. 2013. Obsession in entrepreneurs - towards a conceptualization. Entrepreneurship Research Journal 3(2): 207-237.

[26] Fornell, C. \& Larcker, D.L. 1981. Structural equation models with unobservable variables and measurement errors: Algebra and statistics. Journal of Marketing Research 18(3): 382-388.

[27] Frese, M.J. \& Gielnik, M.M. 2014. The psychology of entrepreneurship. Annual Review of Organizational Psychology and Organizational Behavior 1: 413-438.

[28] Frese, M.J. 2009. Characteristics of active performance and entrepreneurial success. In Toward a Psychology of Entrepreneurship - An Action Theory Perspective Foundations and Trends in Entrepreneurship. pp. 435-494.

[29] Gorgievski, M.J., Bakker, A. \& Schaufeli, W.B. 2011. Work engagement and workaholism: Comparing the selfemployed and salaried employees. The Journal of Positive Psychology 5(1): 83-96.

[30] Greenhaus, J.H., Parasuraman, S. \& Wormley, W.M. 1990. Effects of race on organizational experiences, job performance evaluation, and career outcomes. Academy of Management Journal 33(1): 64-86.

[31] Haber, S. \& Reichel, A. 2005. Identifying measures of small ventures - the case of tourism industry. Journal of Small Business Management 43(3): 257-286.

[32] Hair, J.F., Anderson, R.E., Tatham, R.L. \& Black, W.C. 1998. Multivariate Data Analysis. New Jersey: Prentice Hall.

[33] Hall, D.T. \& Chandler, D.E. 2005. Psychological success: When the career is a calling. Journal of Organizational Behavior 26: 155-176.

[34] Hmieleski, K.M. \& Carr, J.C. 2007. The relationship between entrepreneur psychological capital and well-being. Frontiers of Entrepreneurship Research 27(5): 1-12.

[35] Hmieleski, K.M. \& Corbett, A.C. 2008. The contracting interaction effects of improvisational behavior with entrepreneurial self-efficacy on new venture performance and entrepreneurship work satisfaction. Journal of Business Venturing 23: 482-496.

[36] Holcomb, T.R., Ireland, R.D., Holmes Jr., R.M. \& Hitt, M.A. 2009. Architecture of entrepreneurial learning: exploring the link among heuristics, knowledge, and action. Entrepreneurship Theory and Practice 33(1): 167-192.

[37] Idar, Raduan \& Mahmood, Rosli. 2011. Entrepreneurial and marketing orientations relationship to performance: The SME perspective. Interdisciplinary Review of Economics and Management 1(2): 1-8.

[38] Jain, Ravindra \& Ali, Saiyed Wajid. 2013. Self-efficacy beliefs, marketing orientation and attitude orientation of Indian entrepreneurs. Journal of Entrepreneurship 22(1): 71-95.

[39] Judge, T.A., Bono, J.E., Thorensen, C.J. \& Patton, G.K. 2001. The job satisfaction - job performance relationship: A qualitative and quantitative review. Psychological Bulletin 127(3): 376-407.

[40] Juhdi, H.N. \& Salleh, Aliah H.M. 2009. Brand awareness and brand meaning in cultivating service brand equity for Malaysian higher education. Services Management and Marketing: Studies in Malaysia. UKM-Graduate School of Business, UKM.

[41] Kirca, A.H., Jayachandran, Satish \& Bearden, W.O. 2005. Market orientation: A meta-analytic review and assessment of its antecedents and impact on performance. Journal of Marketing 69(2): 24-41. 
[42] Lerner, J. 2009. Boulevard of broken dreams. Princeton University Press. New jersey.

[43] Levitt, B. \& March, J.G. 1988. Organizational learning. Annual Review of Sociology 14: 319-340.

[44] Liechti, D., Loderer, C. \& Peyer, U. 2011. Luck and Entrepreneurial Success. Conference paper, 2009 Conference of the Academy of Entrepreneurial Finance, the Academy of Behavioral Finance, and INSEAD. France.

[45] Liu, S.S., Luo, X. \& Shi, Yi-Zheng. 2003. Market-oriented organizations in an emerging economy: A study of missing links. Journal of Business Research 56: 481-491.

[46] Lope Pihie, Z.A. \& Baghari, A. 2012. An exploratory study of entrepreneurial attributes among Malaysian university students. Life Science Journal 9(3): 2358-2365.

[47] Luthans, F., Avolio, B.J., Avey, J.B. \& Norman, S.M. 2007. Positive psychological capital: Measurement and relationship with performance and satisfaction. Personnel Psychology 60: 541-572.

[48] Luthans, F., Luthans, K.W. \& Luthans, B.C. 2004. Positive psychological capital: Beyond human and social capital. Business Horizon 47(1): 45-50.

[49] Luthans, F. \& Youssef, C.M. 2007. Psychological Capital. pp. 237-238. New York Oxford University Press.

[50] Lytle, R.S., Hom, P.W. \& Mokwa, M.P. 1998. SERV*OR: A Managerial Measure of Organizational ServiceOrientation. Journal of Retailing 74(4): 455-489.

[51] Lytle, R.S. \& Timmerman, J.E. 2006. Service Orientation and Performance: an Organizational Perspective. Journal of Service Marketing 20(2): 136-147.

[52] Mariussen, A.J., Wheelock, J. \& Baines, S. 1997. The Family Business Tradition in Britain and Norway International Studies of Management in Organizations 27: 64-85.

[53] McCullough, M.E., Emmons, R.A. \& Tsang, Jo-Ann. 2002. The Grateful Disposition: a Conceptual and Empirical Topography. Journal of Personality and Social Psychology 82(1): 112-127.

[54] Menell, P.S. 1998. An Epitaph for Traditional Copyright Protection of Network Features of Computer Software. Antitrust Bulletin 43(3-4): 651-713. Available at http://ssrn.com

[55] Newman, A., Schwarz, S. \& Borgia, D. 2013. How does microfirm enhance entrepreneurial outcomes in emerging economies? The mediating mechanism of psychological and social capital. international Small Business Journal 32(2): 158-179.

[56] Oliveira, P. \& Roth, A.V. 2012. Service Orientation: The Derivation of Underlying Constructs and Measures. International Journal of Operations \& Production Management 32(2): 156-190.

[57] Paladino, Angela. 2007. Investing the Drivers of Innovation and New Product Success: A Comparison of Strategic Orientation. The Journal of Product Innovation Management 24: 534-553.

[58] Peterson, R.A. 1994. A Meta-Analysis of Cronbach's Coefficient Alpha. Journal of Consumer Research 21(2): 381391.

[59] Peterson, S.J., Luthans, F., Avolio, B.J., Walumbwa, F.O. \& Zhang, Zhen. 2011. Psychological Capital and Employee Performance: A Latent Growth Modeling Approach. Personnel Psychology 64(2): 427-450.

[60] Politis, D. 2005. The Process of Entrepreneurial Learning: A Conceptual Framework. Entrepreneurship Theory and Practice 29(4): 399-424.

[61] Poon, J.M.L. 2005. Career Commitment and Career Success: Moderating Role of Emotional Perception. Career Development International 9(4): 374-390.

[62] Poon, J.M.L., Raja Azimah Aminuddin, Saodah Haji Junit. 2006. Effects of Self-Concept Traits and Entrepreneurial Orientation on Firm Performance. International Small Business Journal 24(1): 61-82.

[63] Preacher, K.J. \& Hayes, A.F. 2004. SPSS and SAS Procedures for Estimating Indirect Effects in Simple Mediation Models. Behavior Research Methods, Instruments \& Computers. 36(4): 717-731.

[64] Preacher, K.J., \& Hayes, A.F. 2008. Asymptotic and Resampling Strategies for Assessing and Comparing Indirect Effects in Multiple Mediator Models. Behavior Research Methods 40(3): 879-891.

[65] Ramayah, T., Yan, L.C. \& Sulaiman, M. 2005. SME e-Readiness in Malaysia: Implications for Planning and Implementation. Sasin Journal of Management 11(1): 103-120. 
[66] Rauch, A. \& Frese, M. 2000. Psychological Approaches to Entrepreneurial Success: A General Model and an Overview of Findings. International Review of Industrial and Organizational Psychology pp. 101-142.

[67] Runyan, R.C., Huddleston, P \& Swinney, J.L. 2007. A Resource-Based View of the Small Firm: Using a Qualitative Approach to Uncover Small Firm Resources. Qualitative Market Research: An International Journal 10(4): 390-402.

[68] Salanova, M., Agut, S. \& Peiro, J.M. 2005. Linking organizational resources and work engagement to employee performance and customer loyalty, the mediation of service climate. Journal of Applied Psychology doi:10.1037/0021-9010.6.1217.

[69] Sarasvathy, S.D. 2004. The Questions We Ask and the Question We Care About: Reformulating Some Problems in Entrepreneurship Research. Journal of Business Venturing 19: 707-717.

[70] Schaufeli, W.B., Bakker, A.B. \& Salanova, M. 2006. The Measurement of Work Engagement with a Short Questionnaire: A Cross-National Study. Educational and Psychological Measurement 66(4): 701-716.

[71] Seligman, M.E.P. 2000. Positive psychology. In Seligman, M.E.P. 2000. The Science of Optimism and Hope. Templeton Foundation press. pp: 415-432.

[72] Seligman, M.E.P. \& Csikszentmihalyi, M. 2000. Positive Psychology. American Psychologist 55(1): 5-14.

[73] Shane, S. 2003. A General Theory of Entrepreneurship: The Individual-Opportunity Nexus. Edward Elgar Publishing, Inc. USA.

[74] Simpson, M., Padmore, J. \& Newman, N. 2012. Towards a New Model of Success and Performance in SMEs. International Journal of Entrepreneurial Behaviour \& Research 18(3): 264-285.

[75] Sisodia, R., Wolfe, D.B. \& Sheth, J. 2007. Firms of Endearment. Wharton School Publishing. New Jersey.

[76] Slater, S.F. \& Narver, J.C. 2000. The Positive Effect of a Market Orientation on Business Profitability: A Balanced Replication. Journal of Business research 48: 69-73.

[77] SMI SME Business Directory (Malaysia). 2010.

[78] Sok, P., O'Cass, A. \& Sok, K.M. 2013. Achieving superior SME performance: Overarching role of marketing, innovation, and learning capabilities. Australasian Marketing Journal 21(3): 161-167.

[79] Spicer, D.P. \& Sadler-Smith, E. 2006. Organizational Learning in Smaller Manufacturing Firms. International Small Business Journal 24(2): 133-158.

[80] SSM http://www.ssm.com.my/

[81] Steinman, C., Deshpande, R \& Farley, J.U. 2000. Beyond Market Orientation: When Customers and Suppliers Disagree. Journal of the Academy of Marketing Science 28(1): 109-119.

[82] Stokes, D. \& Blackburn, R. 2002. Learning the Hard Way: The Lessons of Owner-Managers who have Closed their Business. Journal of Small Business and Enterprise Development 9(1): 17-27.

[83] Svendsen, M.F., Haugland, S.A., Gronhaug, K. \& Hammervoll, T. 2011. Marketing Strategy and Customer Involvement in Product Development. European Journal of Marketing 45(4).

[84] Sweetman, D., Luthans, F., Avey, J.B. \& Luthans, B. 2011. Relationship between Positive Psychological Capital and Creative Performance. Canadian Journal of Administrative Sciences 28: 4-13.

[85] Tabachnick, B.G. \& Fidell, L.S. 2001. Using Multivariate Statistics. 4th. Edition. A Pearson Education Company. USA.

[86] Tang, J., Kacmar, K.M. \& Busenitz, L. 2010. Entrepreneurial Alertness in the Pursuit of New Opportunities. Journal of Business Venturing article in press.

[87] Vargo, S.L. \& Lusch, R.F. 2008. Why "service"? Journal of Academy of Marketing Science 36: 25-38.

[88] Wang, C.L. 2008. Entrepreneurial Orientation, Learning Orientation, and Firm Performance. Entrepreneurship Theory and Practice 32(4): 635-657.

[89] Weiner, B. 1985. An Attributional Theory of Achievement Motivation and Emotion. Psychological Review 92(4): 548573.

[90] Yang, Y. \& Green, S.B. 2011. Coefficient Alpha: A Reliability Coefficient for the 21st Century? Journal of Psychoeducational Assessment 29(4): 377-392. 
[91] Zhao, X., Lynch Jr, J.G. \& Chen, Qimei. 2010. Reconsidering Baron and Kenny: Myths and Truths about Mediation Analysis. Journal of Consumer Research 37(2): 197-206.

[92] Zheng, Xin \& Yin, Cui. 2010. Entrepreneurial Orientation, Market Orientation and Firm Performance: The Mediation Role of Organizational Learning. Management and Service Science, International Conference Proceeding, IEEE $p$. $1-4$.

\section{APPENDIX A}

\section{Item Measurements}

\section{Entrepreneurial success}

1. I perceived sufficient income in the first three years of establishment.

2. I perceived having high income for the last few years.

3. I expect having high income for the next following years.

4. I Iam highly satisfied with the success I have achieved.

5. I am highly satisfied with the progress I have made toward meeting my overall goals.

6. I am highly satisfied with the progress I have made toward meeting my goals for income.

7. I am highly satisfied with the progress I have made toward meeting my goals for self-advancement.

8. I am highly satisfied with the progress I have made toward meeting my goals for the development of new skills.

9. I have so much in life to be thankful for.

10. If I have to list everything that I feel grateful for, it would be a very long list.

11. When I look at the world, I don't see much to be grateful for.

12. I am grateful to very wide variety of people.

13. As I get older I find myself more able to appreciate everything that has been part of my life history.

14. Long amounts of time can go by before I feel grateful to something or someone.

15. I have a gut feeling for potential opportunities.

16. I can distinguish between profitable opportunities and not-so-profitable opportunities.

17. I have a knack for telling high-value opportunities apart from low-value opportunities.

18. When facing multiple opportunities, I am able to select the good ones.

\section{Psychological capital}

1. I feel confident analyzing a long-term problem to find a solution.

2. I feel confident in representing my work area in meetings with management.

3. I feel confident contributing to discussions about the organization's strategy.

4. I feel confident helping to set targets/goals in my work area.

5. I feel confident contacting people outside the organization (e.g., suppliers, customers) to discuss problems.

6. I feel confident presenting information to a group of colleagues.

7. If I should find myself in a jam at work, I could think of many ways to get out of it.

8. At the present time, I am energetically pursuing my work goals.

9. There are lots of ways around any problem.

10. Right now I see myself as being pretty successful at work.

11. I can think of many ways to reach my current work goals.

12. At this time, I am meeting the work goals that I have set for myself

13. When I have a setback at work, I have trouble recovering from it, moving on.

14. I usually manage difficulties one way or another at work.

15. I can be "on my own," so to speak, at work if I have to.

16. I usually take stressful things at work in stride.

17. I can get through difficult times at work because I have experienced difficulty before.

18. I feel I can handle many things at a time at this job.

19. When things are uncertain for me at work, I usually expect the best.

20. If something can go wrong for me work-wise, it will because I believe anything bad is possible for me.

21. I always look on the bright side of things regarding my job.

22. I am optimistic about what will happen to me in the future as it pertains to work.

23. In this job, things never work out the way I want them to.

24. I approach this job as if "every cloud has a silver lining." 


\section{Entrepreneurial work engagement}

1. At my work, I feel bursting with energy.

2. I find the work that I do full of meaning and purpose.

3. Time flies when I am working.

4. At my work, I feel strong and vigorous.

5. I am enthusiastic about my ventures.

6. When I am working, I forget everything else around me.

7. My business activities inspire me.

8. When I get up in the morning, I feel like going to work.

9. I feel happy when I have already worked hard enough.

10. I am proud of the work that I do.

11. I am immersed in my work.

12. I can continue working for very long hours.

13. To me, my job is challenging.

14. I get carried away when I am working.

15. At work, I am very resilient, mentally.

16. It is difficult to detach myself from my job.

17. At work, I always persevere, even when things do not go well.

\section{Entrepreneurial learning intensity}

1. I put a great deal to learn business knowledge from direct experience with customers.

2. I put a great deal to learn business knowledge by observing others.

3. I make an effort to take in and digest new knowledge.

4. I make an effort to link new knowledge with my preexisting situation.

5. When in lack of knowledge, I do not think hard to decide on taking opportunities.

6. When in lack of knowledge, I have to make exhaustive analysis.

\section{Service orientation}

1. I am committed in providing resources to enhance employee ability to be excellent.

2. I view customers as opportunities to serve rather than as sources of revenue.

3. I believe that my business exists to serve the needs of my customers.

4. My employees always report that they care for customers.

5. My employees always report that they go extra mile for customers.

6. My employees always report that they go out of their way to reduce inconveniences for customers.

7. Every employee receives personal skill trainings that enhance his/her ability to deliver high quality service.

8. Large amount of time and effort in simulated training activities that help us provide high levels of service.

\section{Market orientation}

1. I continually monitor my customers and competitors to find new ways to improve customer satisfaction.

2. I freely communicate information about successful and unsuccessful customer experiences with every worker across functions.

3. My business strategy for competitive advantage is based on my understanding of customers' needs.

4. My business activities are more customer-focused.

5. My business activities include polling end users at least once per year to assess the quality of products and services.

6. My overall business objectives are driven primarily by customer satisfaction.

7. One of my main concerns is to measure customer satisfaction systematically.

8. I set routine or regular measures of customer service.

9. I believe this business exists primarily to serve customers.

10. Data on customer satisfaction are disseminated at all levels in this business on regular basis.

\section{APPENDIX B}

Factor Analysis: Loadings and Cross-Loadings 


\begin{tabular}{|c|c|c|c|c|c|c|}
\hline & & & ELI & PSYCAP & MO & so \\
\hline FW1 & 0.2218 & 0.1155 & 0.1428 & 0.0754 & 0.0746 & 0.1468 \\
\hline FW2 & 0.4728 & 0.3151 & 0.3282 & 0.2733 & 0.1638 & 0.0133 \\
\hline FW3 & 0.3899 & 0.2259 & 0.3319 & 0.3432 & 0.1855 & 0.0821 \\
\hline OPP1 & 0.4716 & 0.3624 & 0.3646 & 0.367 & 0.3015 & 0.1484 \\
\hline OPP2 & 0.5634 & 0.4762 & 0.4009 & 0.484 & 0.3606 & 0.236 \\
\hline OPP3 & 0.5254 & 0.3786 & 0.4432 & 0.4393 & 0.3718 & 0.1832 \\
\hline OPP4 & 0.5697 & 0.458 & 0.4749 & 0.5215 & 0.3552 & 0.3145 \\
\hline PPG1 & 0.5885 & 0.481 & 0.444 & 0.5592 & 0.3172 & 0.3346 \\
\hline PPG2 & 0.5906 & 0.4761 & 0.4594 & 0.5805 & 0.2655 & 0.4001 \\
\hline PPG3 & 0.4503 & 0.3686 & 0.2309 & 0.423 & 0.174 & 0.1063 \\
\hline PPG4 & 0.7398 & 0.6172 & 0.5346 & 0.6573 & 0.2335 & 0.2699 \\
\hline PPG5 & 0.5544 & 0.5044 & 0.3875 & 0.5464 & 0.1521 & 0.1138 \\
\hline PPG6 & 0.5485 & 0.4208 & 0.3132 & 0.4854 & 0.0937 & 0.1057 \\
\hline PPS1 & 0.6604 & 0.4062 & 0.3757 & 0.4712 & 0.257 & 0.1999 \\
\hline PPS2 & 0.5765 & 0.3668 & 0.3776 & 0.3515 & 0.2207 & 0.1908 \\
\hline PPS3 & 0.5451 & 0.4306 & 0.4005 & 0.3523 & 0.3065 & 0.3114 \\
\hline PPS4 & 0.5760 & 0.3977 & 0.3925 & 0.3858 & 0.2571 & 0.1776 \\
\hline PPS5 & 0.6268 & 0.4857 & 0.4363 & 0.4595 & 0.1823 & 0.2304 \\
\hline EW1 & 0.6264 & 0.7453 & 0.6095 & 0.6233 & 0.4051 & 0.3537 \\
\hline EW10 & 0.5195 & 0.6686 & 0.5003 & 0.5439 & 0.303 & 0.2619 \\
\hline EW11 & 0.3789 & 0.6133 & 0.5084 & 0.5264 & 0.3396 & 0.1894 \\
\hline EW12 & 0.4656 & 0.5141 & 0.4171 & 0.4517 & 0.0827 & 0.1098 \\
\hline EW13 & 0.4461 & 0.5044 & 0.4579 & 0.3935 & 0.3379 & 0.3321 \\
\hline EW14 & 0.3315 & 0.4394 & 0.2693 & 0.3176 & 0.2216 & 0.2763 \\
\hline EW15 & 0.4284 & 0.6285 & 0.3625 & 0.5337 & 0.1481 & 0.2022 \\
\hline EW16 & 0.3647 & 0.5496 & 0.3925 & 0.4329 & 0.1902 & 0.1805 \\
\hline EW17 & 0.408 & 0.6846 & 0.4534 & 0.5623 & 0.1506 & 0.1206 \\
\hline EW2 & 0.6074 & 0.7801 & 0.6246 & 0.6206 & 0.2767 & 0.2387 \\
\hline EW3 & 0.6441 & 0.8004 & 0.5233 & 0.7235 & 0.3045 & 0.366 \\
\hline EW4 & 0.636 & 0.8031 & 0.5854 & 0.7007 & 0.3787 & 0.3508 \\
\hline EW5 & 0.4925 & 0.6936 & 0.505 & 0.5514 & 0.2198 & 0.2266 \\
\hline EW6 & 0.3687 & 0.4938 & 0.4156 & 0.3602 & 0.0598 & 0.1201 \\
\hline EW7 & 0.5972 & 0.7809 & 0.6032 & 0.6148 & 0.3423 & 0.227 \\
\hline EW8 & 0.5843 & 0.7500 & 0.4882 & 0.6247 & 0.2873 & 0.2367 \\
\hline EW9 & 0.5533 & 0.6508 & 0.5639 & 0.5679 & 0.3788 & 0.3392 \\
\hline ELI1 & 0.6035 & 0.6271 & 0.7801 & 0.5536 & 0.4832 & 0.4056 \\
\hline ELI2 & 0.3845 & 0.4489 & 0.6316 & 0.4205 & 0.3524 & 0.1999 \\
\hline ELI3 & 0.6041 & 0.6456 & 0.8680 & 0.5978 & 0.4537 & 0.3224 \\
\hline ELI4 & 0.5365 & 0.579 & 0.8144 & 0.5593 & 0.3502 & 0.2833 \\
\hline ELI5 & 0.3394 & 0.3344 & 0.4344 & 0.3544 & 0.0457 & 0.0937 \\
\hline ELI6 & 0.2947 & 0.1971 & 0.2961 & 0.2896 & 0.0352 & 0.032 \\
\hline PSYCAPC1 & 0.4462 & 0.4747 & 0.3772 & 0.5979 & 0.3766 & 0.2516 \\
\hline PSYCAPC2 & 0.4925 & 0.4896 & 0.4722 & 0.5699 & 0.3088 & 0.1294 \\
\hline PSYCAPC3 & 0.3607 & 0.361 & 0.2365 & 0.5405 & 0.2999 & 0.2262 \\
\hline PSYCAPC4 & 0.45 & 0.4766 & 0.3433 & 0.6301 & 0.2225 & 0.1611 \\
\hline PSYCAPC5 & 0.5651 & 0.5702 & 0.4292 & 0.7383 & 0.2937 & 0.1967 \\
\hline PSYCAPC6 & 0.6022 & 0.6115 & 0.5092 & 0.7504 & 0.3312 & 0.218 \\
\hline PSYCAPH10 & 0.1205 & 0.2341 & 0.1597 & 0.2174 & 0.0024 & 0.027 \\
\hline
\end{tabular}




$\begin{array}{lllllll}\text { PSYCAPH11 } & 0.4215 & 0.4554 & 0.3751 & \mathbf{0 . 6 1 1 6} & 0.3094 & 0.3072 \\ \text { PSYCAPH12 } & 0.5274 & 0.441 & 0.3858 & \mathbf{0 . 4 9 6 2} & 0.3362 & 0.3682 \\ \text { PSYCAPH7 } & 0.53 & 0.549 & 0.5212 & \mathbf{0 . 6 6 7 2} & 0.1933 & 0.2787 \\ \text { PSYCAPH8 } & 0.5704 & 0.6017 & 0.5378 & \mathbf{0 . 6 1 2 3} & 0.3924 & 0.2187 \\ \text { PSYCAPH9 } & 0.5466 & 0.5219 & 0.3647 & \mathbf{0 . 5 9 2 1} & 0.0998 & 0.1493 \\ \text { PSYCAP019 } & 0.5934 & 0.5318 & 0.5212 & \mathbf{0 . 6 8 7 9} & 0.2209 & 0.3386 \\ \text { PSYCAPO20 } & 0.3138 & 0.2181 & 0.2428 & \mathbf{0 . 3 1 8 6} & 0.0932 & 0.19 \\ \text { PSYCAPO21 } & 0.4875 & 0.3821 & 0.425 & \mathbf{0 . 5 7 8 6} & 0.2252 & 0.3462 \\ \text { PSYCAPO22 } & 0.5775 & 0.5289 & 0.5095 & \mathbf{0 . 6 8 9 0} & 0.3196 & 0.3115 \\ \text { PSYCAPO23 } & 0.2601 & 0.1431 & 0.1492 & \mathbf{0 . 3 0 1 9} & 0.0833 & 0.1622 \\ \text { PSYCAPO24 } & 0.5829 & 0.6317 & 0.495 & \mathbf{0 . 6 8 5 3} & 0.353 & 0.2197 \\ \text { PSYCAPR13 } & 0.3422 & 0.3228 & 0.1514 & \mathbf{0 . 3 5 3 9} & 0.181 & 0.2056 \\ \text { PSYCAPR14 } & 0.3768 & 0.4977 & 0.3666 & \mathbf{0 . 5 1 0 7} & 0.2039 & 0.2315 \\ \text { PSYCAPR15 } & 0.031 & \mathbf{0 . 0 5 4} & -0.0091 & \mathbf{0 . 0 2 5 9} & - & -0.1547 \\ \text { PSYCAPR16 } & 0.4543 & 0.5551 & 0.4927 & \mathbf{0 . 5 3 3 6} & 0.3732 & 0.3577 \\ \text { PSYCAPR17 } & 0.293 & 0.3978 & 0.3448 & \mathbf{0 . 4 7 3 7} & 0.2629 & 0.2389 \\ \text { PSYCAPR18 } & 0.3176 & 0.3316 & 0.3042 & \mathbf{0 . 4 8 2 9} & 0.165 & 0.3173 \\ \text { M01 } & 0.2661 & 0.2332 & 0.4125 & 0.2317 & \mathbf{0 . 6 5 5 6} & 0.3141 \\ \text { M010 } & 0.3695 & 0.4749 & 0.3185 & 0.4518 & \mathbf{0 . 6 8 2 6} & 0.5898 \\ \text { M02 } & 0.2081 & 0.2652 & 0.3343 & 0.2904 & \mathbf{0 . 5 8 3 4} & 0.2928 \\ \text { M03 } & 0.3445 & 0.2753 & 0.4125 & 0.3398 & \mathbf{0 . 7 4 7 6} & 0.3333 \\ \text { M04 } & 0.4247 & 0.3194 & 0.398 & 0.3921 & \mathbf{0 . 7 3 5 0} & 0.2825 \\ \text { M05 } & 0.1247 & 0.15 & 0.1782 & 0.1306 & \mathbf{0 . 5 4 7 3} & 0.4386 \\ \text { M06 } & 0.2742 & 0.2495 & 0.2933 & 0.268 & \mathbf{0 . 7 3 8 7} & 0.5176 \\ \text { M07 } & 0.1828 & 0.147 & 0.1237 & 0.249 & \mathbf{0 . 6 4 4 4} & 0.4644 \\ \text { M08 } & 0.2868 & 0.2482 & 0.2339 & 0.3222 & \mathbf{0 . 6 7 3 6} & 0.5379 \\ \text { M09 } & 0.3664 & 0.2971 & 0.3579 & 0.3329 & \mathbf{0 . 7 7 2 1} & 0.5597 \\ \text { S01 } & 0.1916 & 0.2183 & 0.2896 & 0.2849 & 0.5289 & \mathbf{0 . 6 9 1 4} \\ \text { S02 } & 0.1266 & 0.161 & 0.1279 & 0.2076 & 0.2511 & \mathbf{0 . 4 4 5 1} \\ \text { S03 } & 0.2011 & 0.2957 & 0.1454 & 0.316 & 0.4213 & \mathbf{0 . 7 2 0 2} \\ \text { S04 } & 0.1262 & 0.2043 & 0.1217 & 0.2588 & 0.3508 & \mathbf{0 . 6 6 0 5} \\ \text { S05 } & 0.0698 & 0.13 & -0.0174 & 0.1199 & 0.2648 & \mathbf{0 . 5 0 3 4} \\ \text { S06 } & 0.2268 & 0.2273 & 0.268 & 0.2087 & 0.3512 & \mathbf{0 . 7 8 6 5} \\ \text { S07 } & 0.401 & 0.3076 & 0.3858 & 0.3635 & 0.5589 & \mathbf{0 . 8 4 9 0} \\ \text { S08 } & 0.4911 & 0.3991 & 0.4847 & 0.4317 & 0.5182 & \mathbf{0} .8007\end{array}$

